\title{
Проявление геохимической специализации пород питающих провинций в элементном составе донных отложений Иркутского водохранилища
}

Карнаухова Г.А., Штельмах С.И., Пашкова Г.В., Пантеева С.В.

ФГБУН Институт земной коры СО РАН, Иркутск, karnauh@crust.irk.ru; fotina78@gmail.com; pashkova.gv@yandex.ru; panteeva@crust.irk.ru

Аннотация. Основным источником формирования донных отложений Иркутского водохранилища являются его абразионные берега, сложенные юрскими песчаниками и четвертичными делювиальными суглинками. Из материала абразии берегов в водохранилище формируются три основных типа донных отложений - пески, крупные алевриты и мелкоалевритовые илы. Большая часть поступающих в составе абразионного материала химических элементов концентрируется в донных отложениях водохранилища и проявляется в виде преобладания элементов литофильной и халькофильной групп, что отражает геохимическую специализацию абрадируемых пород, входящих в состав Восточно-Сибирской литофильно-халькофильной геохимической провинции.

Ключевые слова: водохранилище, абразия, донные отложения, элементный состав.

\section{Occurrence of the geochemical specialization of the distributive province rocks in the elemental composition of the bottom sediments of the Irkutsk reservoir}

\author{
Karnaukhova G.A., Shtel'makh S.I., Pashkova G.V., Panteeva S.V. \\ (FSBIS) Institute of the Earth's crust SB RAS, Irkutsk, karnauh@crust.irk.ru
}

Annotation. The Irkutsk reservoir abrasive banks composed of the Jurassic sandstones and the Quaternary deluvial loess loams are the main source of the bottom sediments. Three main types of the bottom sediments form from the abrasion material of banks. The sands, the large silts, and the muds with the small silts belong to these types. The most part of the chemical elements from the abrasive material concentrates in the bottom sediments of the reservoir where the prevalence of the elements of lithophylic and chalcophylic groups is observed. It reflects that the geochemical specialization of the eroding rocks located on the territory of the East Siberian lithophylic-chalcophylic geochemical province.

Keyword: reservoir, abrasion, bottom sediments, elemental composition.

\section{Введение}

Одним из масштабных видов деятельности человека стало зарегулирование стока реки Ангары и создание в Иркутской области одного из крупнейших в мире Ангарского каскада искусственных водоемов, включающих Иркутское, Братское, Усть-Илимское и Богучанское водохранилища. Образование водохранилищ изменило природные потоки мобилизации, миграции, распределения вещества литосферы и его геохимический состав в южной части Сибирской платформы. Активизация потоков вещества и его аккумуляция в пределах искусственных водоемов связана с абразией материала, слагающего берега этих водоемов, с составом и свойствами пород, подвергающихся размыву. В задачу исследования входило изучение степени проявления геохимической специализации пород питающих провинций в элементном составе донных отложений Иркутского водохранилища - головного в Ангарском каскаде.

\section{Методы исследования}

Основными методами изучения состава пород питающих провинций и донных отложений Иркутского водохранилища являются экспедиционные исследования, лабораторно-аналитические методы, методы расчета, проведенные в период с 1972 по 2018 гг. Отбор образцов донных отложений проводился с борта НИСа грунтоотборной трубкой ПИ-27-II, для работы на малых глубинах с лодки были задействованы грунтоотботники различных модификаций и дночерпатель. 
В лабораторных условиях, с использованием оборудования ЦКП ИЗК СО РАН «Геодинамика и геохронология», выполнялось определение гранулометрического состава образцов ситовым, Сабанина, пипеточным и комбинированным методами. При изучении химического состава образцов использовались методы традиционного полного химического анализа и инструментальные методы, в том числе метод количественного спектрального рентгенофлуоресцентного анализа (РФА), основным преимуществом которого является определение содержаний макро- и микроэлементов в исследуемых образцах без их разрушения.

\section{Результаты и обсуждение}

После создания Иркутского водохранилища его берегами стали поверхности и склоны террас реки Ангары. В береговой зоне водохранилища получили распространение новые процессы - абразия, перемещение и аккумуляция продуктов размыва. Интенсивность абразионных процессов находится в прямой зависимости от гидродинамических условий (волновой и уровенный режимы), геоморфологических и инженерно-геологических условий береговой зоны, литолого-геохимического состава размываемых пород. Абразионные берега на Иркутском водохранилище занимают 150 км береговой линии (примерно 54 \% от ее общей длины), их образование происходит в отложениях юрского и четвертичного возраста. Согласно материалам, представленным в коллективном труде (Атлас..., 2004), по геохимической специализации породы юрского и четвертичного возраста юга Сибирской платформы входят в состав Восточно-Сибирской литофильно-халькофильной геохимической провинции.

В породах юрского возраста, сложенных полевошпатово-кварцевыми и кварц-полевошпатовыми среднезернистыми с карбонатно-глинистым или глинисто-слюдистым цементом песчаниками присаянской и черемховской свит, берега Иркутского водохранилища формируются по левобережью. В составе песчаников песчаная фракция, представленная кремнеземом, занимает 88.2 \%, на алевритовую фракцию приходится $2.53 \%$, на пелитовую $-9.27 \%$.

Общим для всех разновидностей юрских песчаников является определенное однообразие их химического состава, незначительное количество водорастворимых солей, связанное с пресноводными условиями осадконакопления, и слабая карбонатность. Песчаники юры относятся к породам Предсаянской литофильной области Восточно-Сибирской литофильно-халькофильной геохимической провинции. Характерным для песчаников является лидирование элементов из литофильной и халькофильной групп. Из породообразующих (\%) это $\mathrm{SiO}_{2}$ (79.44), $\mathrm{Fe}_{2} \mathrm{O}_{3}(5.23), \mathrm{CaO}$ (2.18), $\mathrm{MnO}$ $(0.75)$ и $\mathrm{TiO}_{2}(0.26)$. Среди микроэлементов ведущими являются (мг/кг) $\mathrm{V}-55, \mathrm{Cr}-50$ из литофильной группы и из халькофильной - Zn (55 мг/кг). В рассеянных элементах наибольшую концентрацию имеют литофильные (мг/кг) $\mathrm{Sr}-349, \mathrm{Zr}-210, \mathrm{Ce}-78$.

По правобережью берега водохранилища формируются в четверичных делювиальных отложениях, представленных в основном лессовидными суглинками. В составе суглинков преобладает алевритовая фракция (50.3\%), несколько меньше приходится на песчаную фракцию - 46.2 \%, доля пелита в суглинках невелика $-3.5 \%$.

Суглинки относятся к отложениям Ангаро-Ленской литофильно-халькофильной области Восточно-Сибирской литофильно-халькофильной геохимической провинции. Суглинки более обогащены элементами литофильной группы по сравнению с песчаниками. К основным окислам относятся (\%) $\mathrm{SiO}_{2}$ (62.78), $\mathrm{Fe}_{2} \mathrm{O}_{3}(7.30), \mathrm{CaO}(2.65), \mathrm{TiO}_{2}(1.01)$ и $\mathrm{MnO}$ (0.136). Ведущими микроэлементами в литофильной группе являются (мг/кг) $\mathrm{Cr}-150, \mathrm{~V}-120$, а также $\mathrm{Ni}-83$ из сидерофильной группы. Суглинки менее обогащены рассеянными элементами по сравнению с их содержанием в песчаниках. Среди рассеянных элементов лидируют элементы литофильной группы (мг/кг) $\mathrm{Zr}-305$, $\mathrm{Sr}-180, \mathrm{Rb}-76$.

Ежегодно в результате абразии в водохранилище поступает около 240 тыс. т элементов основного состава, из них от размыва юрских песчаников около 190 тыс. т, в том числе более 160 тыс. т силикатов. Гораздо меньше поступление в водохранилище элементов основного состава из четвертичных суглинков. В составе размытого материала в водохранилище поступают и микроэлементы, 
составляя около 76 т/год. Среди них лидируют $\mathrm{Ni}, \mathrm{Zn}, \mathrm{Cu}$, однако, большая часть этих элементов переходит во взвешенное состояние и сбрасывается с водой в нижний бьеф Иркутского водохранилища (Карнаухова, 2018).

Из материала абразии берегов формируются донные отложения Иркутского водохранилища, представленные песками, крупными алевритами и мелкоалевритовыми илами, геохимический состав которых определяется элементным составом терригенных частиц, слагающих породы питающих провинций, и, в той или иной степени, отражающим их геохимическую специализацию.

Пески, входящие в состав донных отложений, вне зависимости от состава исходного материала, являются среднезернистыми. Пески, формирование которых связано с абразией песчаников, более насыщены (\%) $\mathrm{SiO}_{2}(68.5)$ и $\mathrm{TiO}_{2}(1.04)$. Пески, образованные в результате абразии суглинков, более обогащены (\%) $\mathrm{Fe}_{2} \mathrm{O}_{3}(5.63), \mathrm{MnO}(0.187), \mathrm{CaO}$ (2.65) при довольно высоком содержании $\mathrm{SiO}_{2}$ (таблица).

Таблица. Содержание окислов в породах береговых уступов и донных отложениях Иркутского водохранилищ, \%.

Table. The content of oxides in rocks of coastal ledges and bottom sediments of the Irkutsk reservoir, \%.

\begin{tabular}{|c|l|l|l|l|l|l|}
\hline Абрадируемая порода & Тип донных отложений & $\mathrm{SiO}_{2}$ & $\mathrm{Fe}_{2} \mathrm{O}_{3}$ & $\mathrm{CaO}$ & $\mathrm{TiO}_{2}$ & $\mathrm{MnO}$ \\
\hline \multirow{3}{*}{ Песчаники } & Пески & 68.5 & 4.36 & 2.61 & 1.04 & 0.095 \\
\cline { 2 - 8 } & Крупные алевриты & 66.4 & 5.62 & 2.37 & 0.93 & 0.114 \\
\cline { 2 - 8 } & Мелкоалевритовые илы & 26.48 & 3.93 & 2.46 & 0.87 & 0.078 \\
\hline \multirow{5}{*}{ Суглинки } & Пески & 51.9 & 5.63 & 2.65 & 0.96 & 0.187 \\
\cline { 2 - 7 } & Крупные алевриты & 32.4 & 5.54 & 3.75 & 0.97 & 0.281 \\
\cline { 2 - 7 } & Мелкоалевритовые илы & 20.1 & 5.44 & 2.70 & 0.91 & 0.093 \\
\hline
\end{tabular}

В песках, образованных из песчаников, наиболее активно накапливаются элементы литофильной группы (мг/кг) - Cr (180) и V (100), а также халькофильной - $\mathrm{Pb}(22)$, значительно превышая их концентрацию в исходном материале. Более слабо аккумулируются $\mathrm{Cu}$ (17) и Со (13) (рис. 1 А). В песках, образование которых связано с размывом суглинков, концентрация элементов литофильной группы в целом соответствует их содержанию в размываемых суглинках береговой зоны. В песчаном материале активно накапливается (мг/кг) Zn (59) и Со (25), а также $\mathrm{Ni}$ (62) и Со (25) (рис. 1 Б).

На пески, формирующиеся из размываемых песчаников, приходятся наибольшие концентрации рассеянных литофильных элементов (мг/кг) $\mathrm{Zr}$ (490), $\mathrm{Sr}$ (310), Th (11), La (45), Nd (46). При этом пески обеднены As - 3.2. В песках же, образующихся из суглинков, выше из литофильной группы содержания $\mathrm{Rb}$ (70), $\mathrm{Nb}$ (15), а также элементов халькофильной группы - Ga (12), As (4.4) (рис. 2).

Крупные алевриты в своем фракционном составе имеют абсолютное преобладание алевритовой фракции, составляющей $80.9 \%$ при абразии песчаников и $80.0 \%$ - при поступлении из размываемых суглинков. Концентрации микроэлементов в донных осадках на участках размыва песчаников значительно выше исходного материала, а на участках с абразией суглинков - различия с исходным материалом несущественны. Среди других типов осадков, вне зависимости от состава исходного материала, крупные алевриты являются самыми активными накопителями микроэлементов, особенно $\mathrm{Cr}, \mathrm{V}$, а также $\mathrm{Zn}, \mathrm{Ni}, \mathrm{Pb}$. При этом на участках размыва песчаников содержание микроэлементов незначительно отличается от содержания таковых на участках размыва суглинков. Лишь несколько выделяется $\mathrm{V}$, имея 130 мг/кг, на участках размыва песчаников, против 116 мг/кг - при абразии суглинков (см. рис. 1).

Содержание рассеянных элементов в крупных алевритах в большинстве случаев превышает их концентрацию в исходном материале. Так, при абразии песчаников содержание в осадках составляет (мг/кг) для $\mathrm{Zr}-272, \mathrm{Rb}-74, \mathrm{Y}-56, \mathrm{Nd}-34$. Крупные алевриты, формирующихся из суглинков, активнее накапливают (мг/кг) $\mathrm{Zr}$ (340), $\operatorname{Sr}(294), \operatorname{Ce}(94)$, чем этот тип осадков на участках 


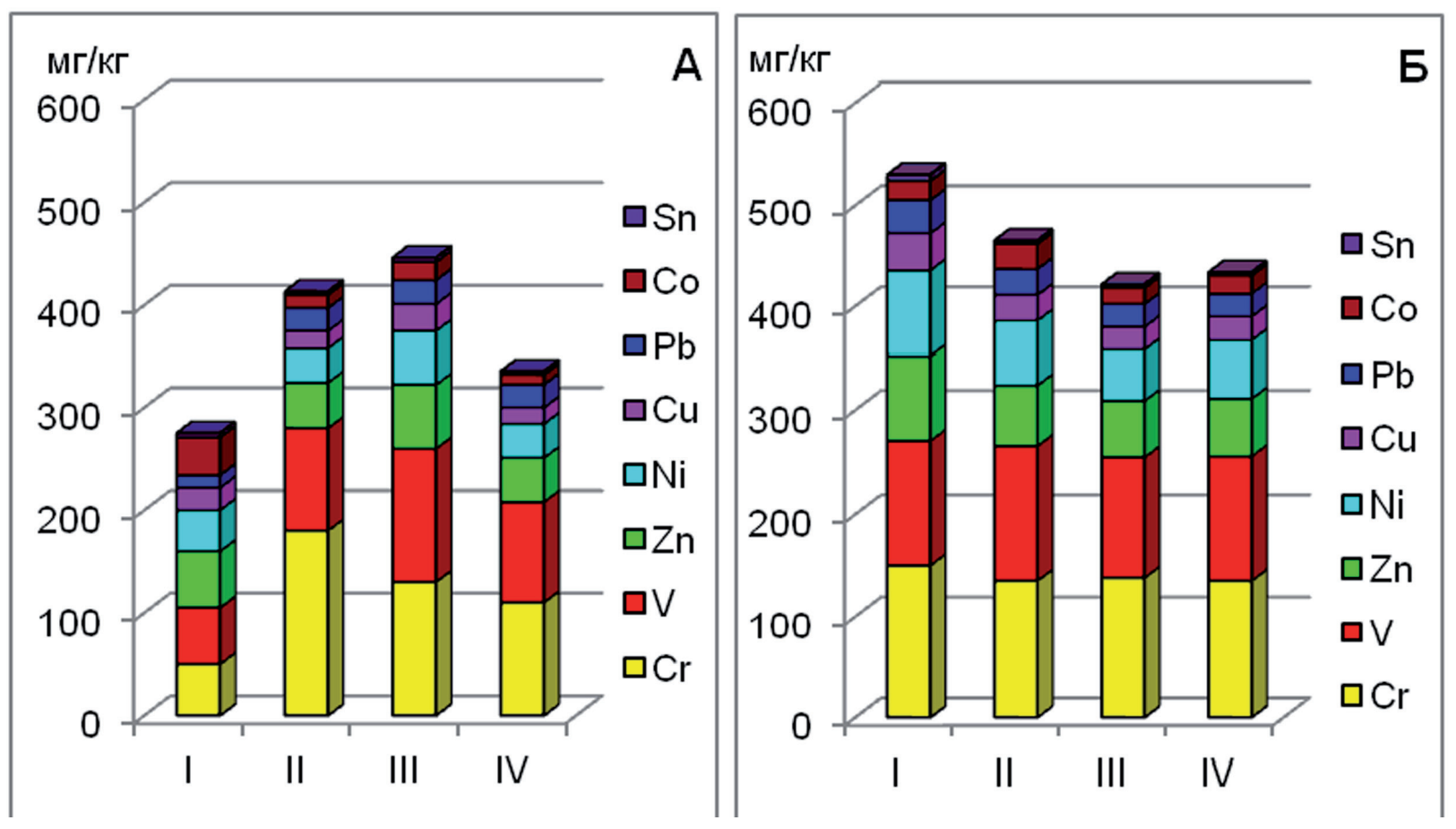

Рис. 1. Распределение микроэлементов в донных отложениях Иркутского водохранилища на участках абразии (мг/кг): А - юрских песчаников, Б - четвертичных суглинков.

Береговой уступ: I - абрадируемая порода; донные отложения: II - пески; III - крупные алевриты; IV - мелкоалевритовые илы.

Fig. 1. Distribution of trace elements in bottom sediments of the Irkutsk reservoir in areas of abrasion ( $\mathrm{mg} / \mathrm{kg})$ : A - Jurassic sandstones, B - Quaternary loams.

Symbols: coastal ledge: I - abraded rock; bottom sediments: II - Sands; III - large silt; IV - fine silt.

размыва песчаников. Присутствие же халькофильных Ga и As одинаково с их содержанием в песках (см. рис. 2).

Мелкоалевритовые ильl, образование которых связано с размывом песчаников, имеют минимальное содержание песчаной фракции (1.5\%) и высокое содержание тонкодисперсных частиц (65.4 \%). Эти илы обеднены микроэлементами, особенно из литофильной группы, по сравнению с таковыми, образование которых связано с абразией суглинков. Так, ванадий имеет самые низкие концентрации среди всех типов осадков в водохранилище (98 мг/кг). Более активно накапливаются элементы халькофильной группы - Zn (43 мг/кг) и $\mathrm{Pb}(22$ мг/кг).

Мелкоалевритовые илы, образование которых связано с разрушением суглинков, имеют примерно равные содержания алевритовой и пелитовой фракций и довольно высокое содержание песчаной фракции. Содержание окислов, за исключением $\mathrm{SiO}_{2}$, в этих илах значительно выше таковых, но формирующихся из песчаников. Кроме того, такие илы являются более обогащенными элементами литофильной группы, чем мелкоалевритовые илы на участках размыва песчаников. По концентрации элементов в сидерофильной и халькофильной группах мелкоалевритовые илы приближаются к их содержанию в песках (см. рис. 1).

Особых различий в концентрациях рассеянных элементов литофильной группы в мелкоалевритовых илах, формирующихся как их размываемых песчаников, так и размываемых суглинков, не отмечается. Так, одинаково содержание (мг/кг) Zr (300), Th (8), Nd (32), либо есть некоторое превышение концентраций в мелкоалевритовых илах, образованных из суглинков. Содержание элементов халькофильной группы в мелкоалевритовых илах на участках абразии суглинков несколько превышает их концентрацию в илах, формирующихся из песчаников (см. рис. 2). 


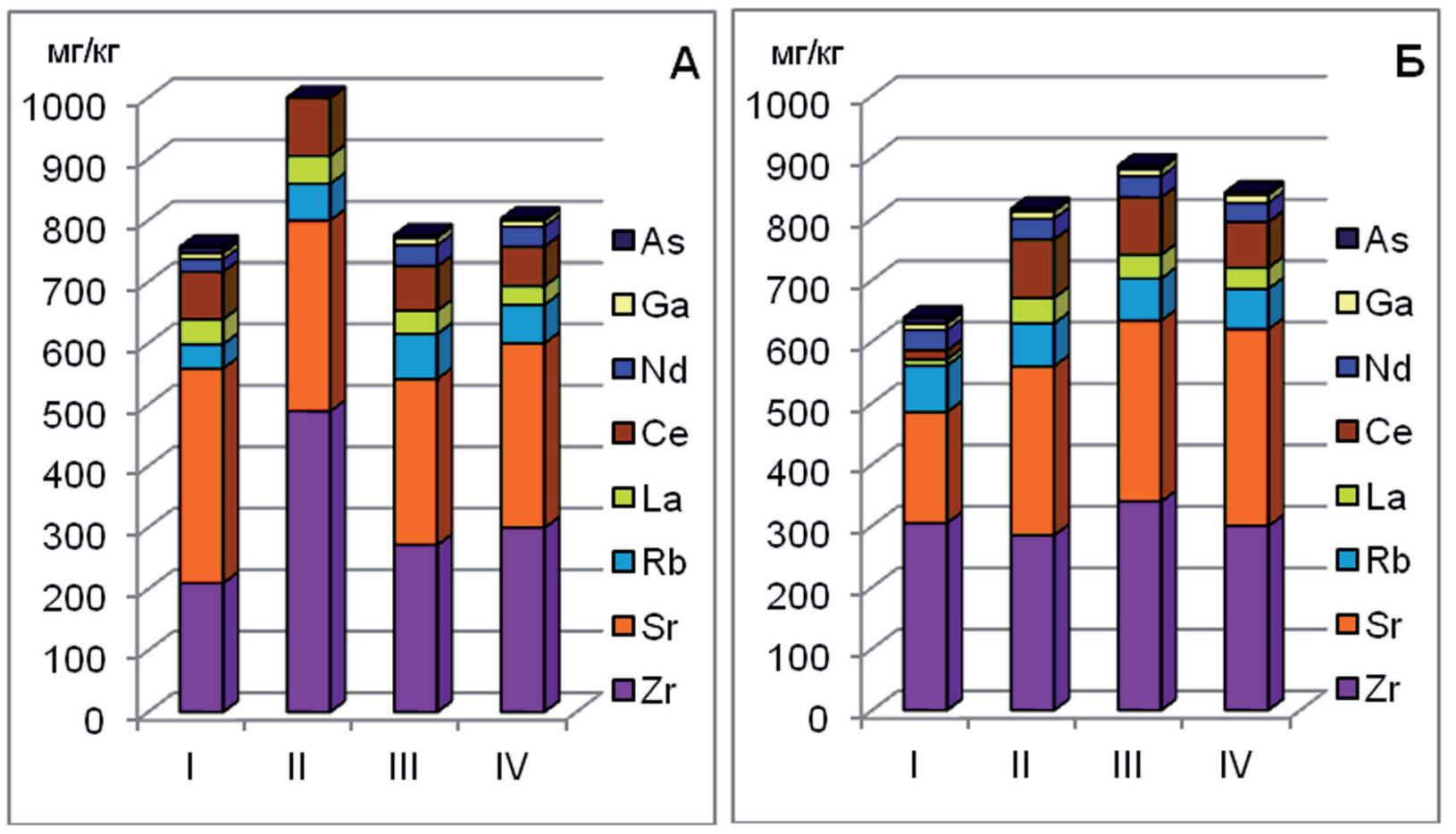

Рис. 2. Распределение рассеянных элементов в донных отложениях Иркутского водохранилища на участках абразии (мг/кг): А - юрских песчаников, Б - четвертичных суглинков.

Условные обозначения: см. рис. 1.

Fig. 2. Distribution of scattered elements in the bottom sediments of the Irkutsk reservoir in the areas of abrasion (mg/kg): A - Jurassic sandstones, B - Quaternary loams.

Symbols: see Fig. 1.

\section{Заключение}

Полученные результаты свидетельствуют о том, что основным источником поступления осадкообразующего материала в Иркутское водохранилище являются абразионные берега, сложенные юрскими песчаниками и четвертичными делювиальными суглинками, входящими в состав ВосточноСибирской литофильно-халькофильной геохимической провинции. Из материала абразии берегов в водохранилище формируются три основных типа донных отложений - пески, крупные алевриты и мелкоалевритовые илы. Большая часть поступающих в составе абразионного материала химических элементов концентрируется в донных отложениях водохранилища и отражает геохимическую специализацию пород, слагающих абразионные берега этого искусственного водоема.

Работа выполнена при финансовой поддержке РФФИ (гранты 18-05-00101-a, 14-05-00079-a, 11-05-00194-a).

\section{Литература}

1. Атлас. Иркутская область: экологические условия развития. М.-Иркутск: Роскартография. ИГ СО РАН им. В.Б. Сочавы. 2004. 90с.

2. Карнаухова Г.А. Изменение гидрохимического состава воды в процессе эксплуатации Иркутского водохранилища // Метеорология и гидрология. 2018. № 7. С. 87-96. 